\title{
A Recumbent Trike Design with Maximum Performance and Vehicle Dynamics Analysis
}

\author{
Dwaipayan Roy Chowdhury ${ }^{1}$, Aditya Mitra ${ }^{2}$ \\ Student of Mechanical Engineering, Dayananda Sagar College of Engineering, Bangalore ${ }^{1,2}$
}

\begin{abstract}
The vehicle is designed based on an International Trike competition called ASME HPVC. The vehicle was designed to excel in speed, handling, efficiency, practicality and safety as these aspects will be tested in the competition. The team has also put in a lot of effort in the innovative side of the design as we strive to create a unique design that set us apart from other competitors. The design of the vehicle consists of background research, concept generation and analysis and testing to ensure the best possible design. To simplify the design process, the team was divided into five subsections with a single team member in charge of each section. These sections include frame, fairing, steering, braking and drive train. For each subsection, design concepts were generated and evaluated to make the best selection. The team also consists of a subsection dedicated only for innovation which creates inventive technology to improve the design of our vehicle. The vehicle is a front faired tadpole trike with a lightweight aluminum frame constructed from 6061-T6 tubing having a total weight of $25 \mathrm{~kg}$. The front faring creates the perfect aerodynamic structure. Vehicle is designed to be safe and rider is protected by a rollover protection system (RPS) which is designed to meet the ASME HPVC requirements with a minimum safety factor of 1.9 .
\end{abstract}

Keywords: Recumbent Trike, Ackermann Angle, Tadpole trike, Vehicle testing, Roll-over protecting system

\section{INTRODUCTION}

The objective is to design and fabricate a Human Powered Vehicle which has the attributes are to design a vehicle with optimum performance, to reach a speed of $55+\mathrm{kmph}$ and to gain $0-40 \mathrm{kmph}$ in $14 \mathrm{sec}$. recumbent design with a low centre of gravity with emphasis on safety of the rider and ergonomics. The motive of an HPV is a safe, ergonomic and an efficient replacement for an automobile. An efficient HPV would give maximum output with minimum effort from the rider. There are many different types of HPV's, but the research is leaned toward trikes which have proved to be both ergonomic due to their recumbence and are also performance oriented. We have observed that the uncommonly high speed imparted to recumbent human powered vehicles is due to their low centre of gravity, aerodynamic shape and a fairing which reduces drag. A rollover protection system and the fairing would provide the safety that generally lacks in normal bicycles. The choice of Tadpole trike has been done after research and by examining various reports. From there, it has been involved in the improvement of this design and fabrication process by critical evaluation of aspects like safety, endurance, manoeuvring and comfort of our HPV. Apart from the Tadpole configuration and direct knuckle steering, this HPV is entirely a new design and fabricated in this academic year (2018-19). There has been no reuse of any components from other previous HPVs

\section{PRIOR DESIGN WORK}

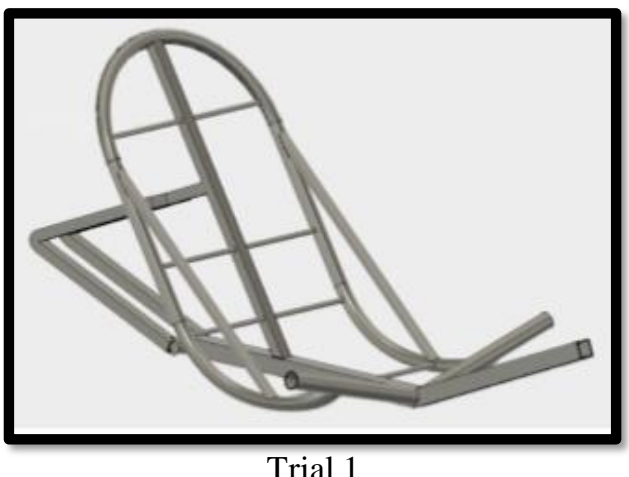

Trial 1 


\section{International Advanced Research Journal in Science, Engineering and Technology}

Vol. 6, Issue 1, January 2019

Firstly, considering the design of the frame, referring to the figures we can observe that the current design is lower lined, and the recumbent angle has been increased to 130o. The centre of gravity as noticed is considerably lower which prevents roll over. A bent X-Member has been incorporated to reduce stress concentration and increase load bearing property of the frame. The use of only front fairing as opposed to the full fairing used in last year's vehicle. Front fairing reduces aerodynamic drag and also reduces cost of production. Overall design is improved in design and fabrication aspects to optimize performance of the trike.

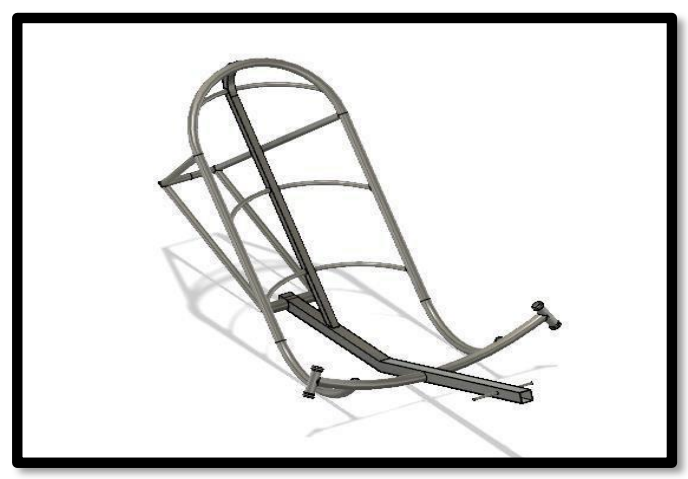

Final Design

Conceptual Development and Selection method For the concept development of our HPV, the whole vehicle was divided into subsystems and analysed individually. The selection of each aspect of our HPV was done after thorough research and analysis. Several studies were done to conclude on the final design aspects of our vehicle.

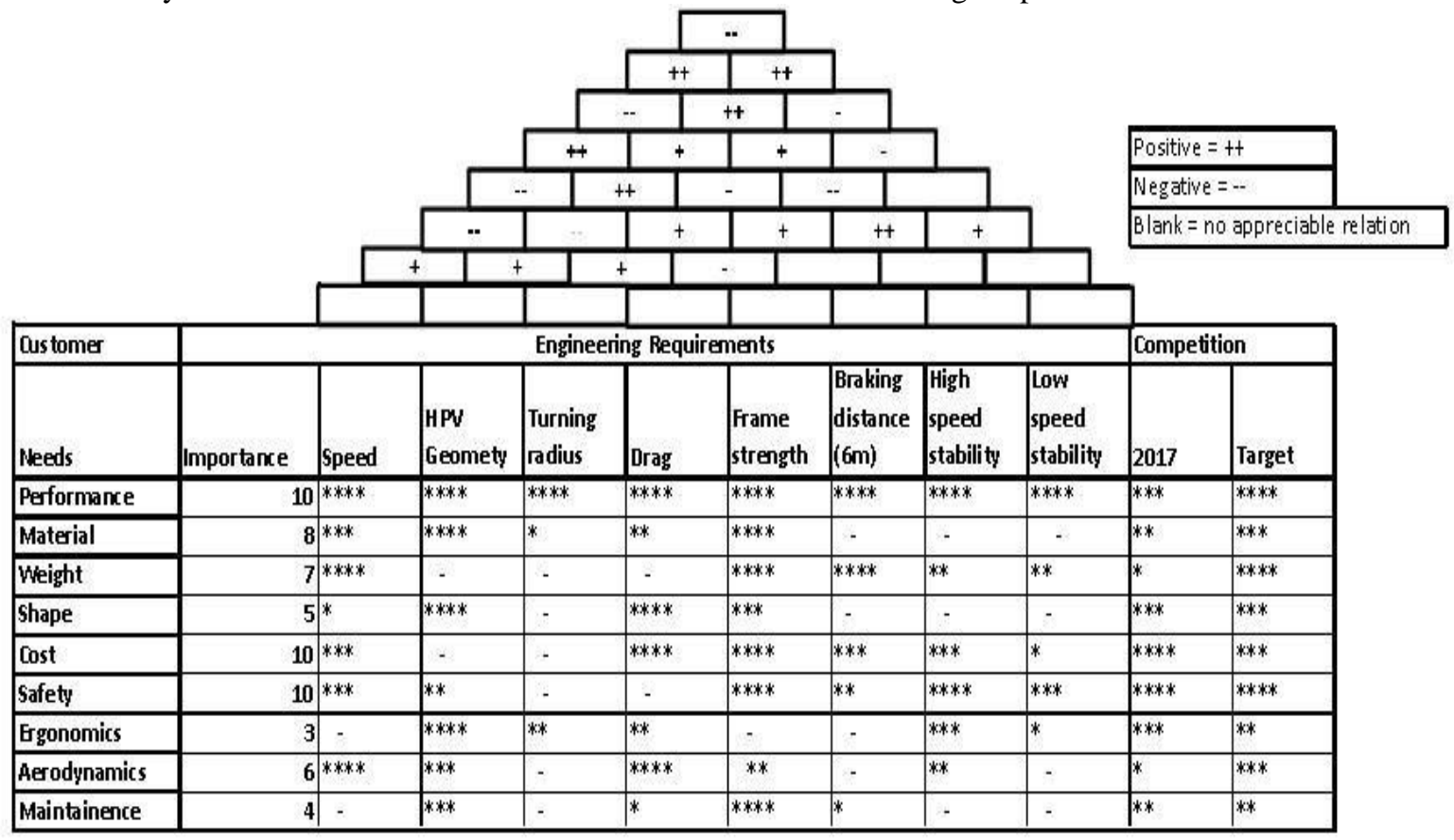

\begin{tabular}{|l|l|l|l|l|l|l|l|l|l|l|l|}
\hline \multicolumn{2}{|c|}{ Competition } \\
\hline 2017 & & $25 \mathrm{~km} / \mathrm{hr}$ & & $7.2 \mathrm{~m}$ & & & $5.7 \mathrm{~m}$ & & & & \\
\hline Target (2018) & & $50 \mathrm{~km} / \mathrm{hr}$ & & $4.8 \mathrm{~m}$ & & & $5 \mathrm{~m}$ & & & & \\
\hline
\end{tabular}

High importance $=* * * *$




\section{International Advanced Research Journal in Science, Engineering and Technology}

Vol. 6, Issue 1, January 2019

The chart below shows the design considerations and the requirements which were mapped out to compare and prioritise aspects to meet design specifications. The factors relevant to the design and construction of the trike were specified and a product design was accomplished accordingly. The design specifications have been mentioned in the following section. The matrices below have been considered to decide the type of frame and the steering configuration of the trike using an efficient marking system and a decision matrix which comprises of the aspects on which both the configurations depend on.

\begin{tabular}{|l|r|l|r|}
\cline { 2 - 5 } \multicolumn{1}{c|}{} & Overseat steering & Underseat steering & Direct Knuckle steering \\
\hline Ease of operation & 4 & 3 & 5 \\
\hline Ease of build & 2 & 2 & 4 \\
\hline Low cost & 4 & 3 & 4 \\
\hline Accomodate with & 3 & 5 & 3 \\
fairing & 4 & 3 & 4 \\
\hline Comfortable & 4 & 2 & 5 \\
\hline Sturdy & 4 & 4 & 4 \\
\hline Safety & 25 & 22 & 29 \\
\hline Total & & & \\
\hline
\end{tabular}

Decision matrix for steering

\section{DESIGN DESCRIPTION}

\section{Frame Design}

The frame is of a tadpole tricycle mainframe with the required RPS for safety. The frame must have optimum strength and minimum points of stress concentration hence uniform stress distribution across the frame. The fabrication of the frame involved tube bending, welding etc. The fame material chosen is Aluminium 6061 T6. The frame includes the following component as shown below. With a rectangular or square cross section of the tubes it is possible to obtain a much higher moment of inertia and polar moment of inertia in a specific plane which will result in a greater resistance to both torsion and bending deflections. With the square flat surfaces, this design will allow for simplified seat integration and manufacturing. The angle of recumbence is $130 \mathrm{o}$. The wheel base of the giver design is $1.916 \mathrm{~m}$; the model caster is $14 \mathrm{o}$, the wheel track $1.20 \mathrm{~m}$, the ground clearance $125 \mathrm{~mm}$, the center of gravity without the rider is located $1.06 \mathrm{~m}$ from the front and $383 \mathrm{~mm}$ from the ground. The weight distribution is $66 \%$ on the front wheels and $33 \%$ on the rear wheel. All these features contribute towards a performance oriented ergonomic design with an optimum safety factor.

\begin{tabular}{|c|c|c|c|}
\hline & \multicolumn{3}{|c|}{ Fame configuration } \\
\hline & Tadpole & Delta & 2 wheel \\
\hline Speed & 0 & 1 & 2 \\
\hline Drag & -1 & 0 & 1 \\
\hline Weight & 1 & 0 & 2 \\
\hline Reliability & 2 & 2 & -2 \\
\hline Maneuverability & 0 & 0 & 1 \\
\hline Ease of entry or exit & 1 & 1 & -3 \\
\hline Ergonomics & 1 & 1 & c \\
\hline Portability & 0 & 0 & L \\
\hline Manufact urability & 1 & 1 & 2 \\
\hline Repairability & 0 & 0 & 1 \\
\hline Price & 1 & 1 & 2 \\
\hline Appearance & 0 & 0 & [ \\
\hline Safety & 3 & 2 & -2 \\
\hline & 0.85 & 0.825 & 0.4 \\
\hline
\end{tabular}




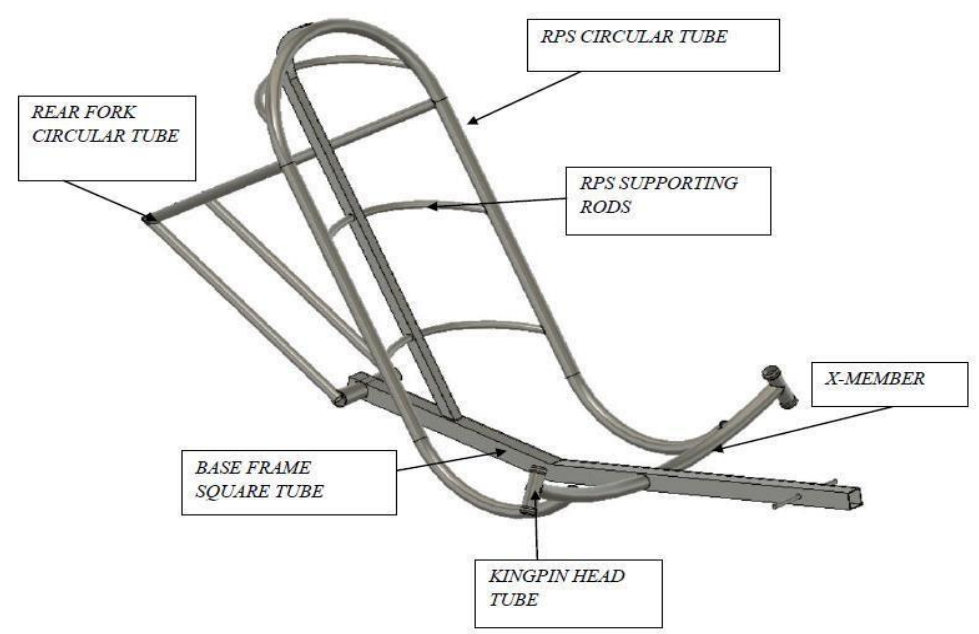

\section{Steering}

Given a tadpole tricycle design, many steering methods have already been implemented. For example under seat steering, over steering, lean steering, knuckle steering and so on. After thorough research direct knuckle steering was chosen as it is simple to incorporate, effective and can be modified easily as per the driver's needs. This steering system consists of a direct steer handle combination, which also holds the brake and shifter levers. During design of the steering, the important factors considered were the kingpin alignment, camber, caster angle and Ackerman compensation. Negative camber has been considered as it improves stability and uniform load distribution on wheels. Having a drastic negative camber helps keep more of the force in the vertical axis of the wheel during turns when there is maximum side loading on the wheels. The negative camber angle considered is 107.50 . To apply proper Ackerman compensation the pivot brackets connecting the rear wheel were aligned to point towards the centre axle of the rear wheel, as shown. This helps reduce the effects of tire rubbing during cornering. Considering all the features, toe in configuration has been achieved as shown in Figure

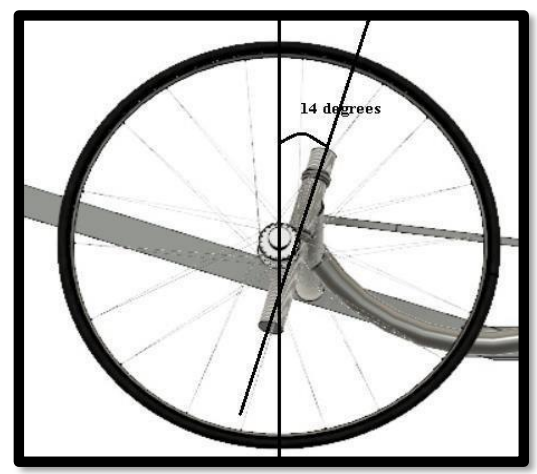

Caster Angle

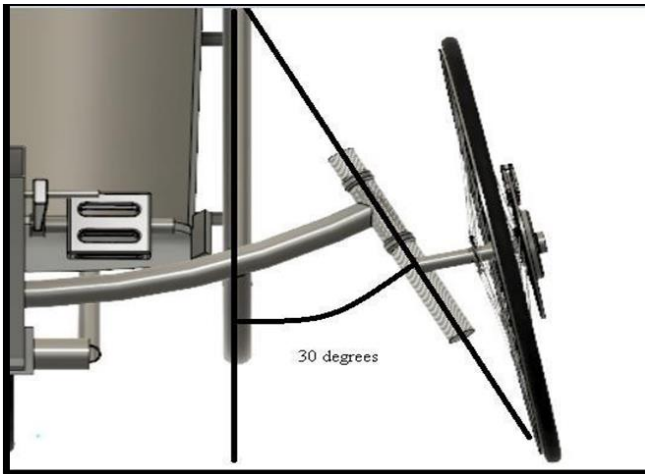

Kingpin Representation 
Vol. 6, Issue 1, January 2019

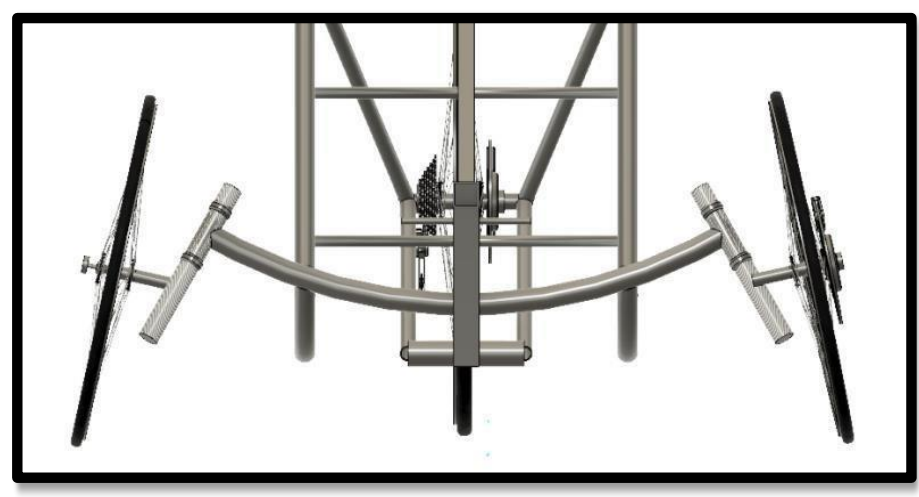

\begin{tabular}{|l|l|}
\hline Kingpin Angle $=30^{\circ}$ & Caster Angle $=14^{\circ}$ \\
\hline $\begin{array}{l}\text { This is the angle of the pivot axis from vertical } \\
\text { viewing from the front. }\end{array}$ & $\begin{array}{l}\text { This angle is the Kingpin plane relationship to the } \\
\text { wheel contacting the road. }\end{array}$ \\
$\begin{array}{l}\text { With the geometry given, the kingpin angle becomes } \\
\text { A caster of } 14^{\circ} \text { has been used for our trike which also } \\
\text { contributed to the toe in configuration of the trike. } \\
\begin{array}{l}\text { Center point steering is desirable because it allows for } \\
\text { more precise and efficient steering }\end{array}\end{array}$ & \\
\hline
\end{tabular}

\section{Braking}

Braking mechanism includes application of friction or resistance to a turning wheel causing it to slow down and eventually stop, creating heat as a by-product. The type of brake used is chosen by comparing the properties of the following 2 types of brakes. According to the comparative study, the disc brakes were chosen for our design. Brakes are applied to all the three wheels of the trike. The brakes of the two front wheels have been combined and connected to a single brake wire to simplify usage of brakes and providing easy access to the rider while braking.

\begin{tabular}{|l|l|}
\hline Disc brakes & Drum brakes \\
\hline Flat friction pad & Semicircular friction pad \\
Lighter in weight & Heavier in weight \\
Rapid heat dissipation & Slow heat dissipation \\
More efficient & Less efficient \\
Effective even during repeated & Lose effectiveness due to \\
application & continuous application \\
\hline
\end{tabular}

Difference between Disc and Drum Brake

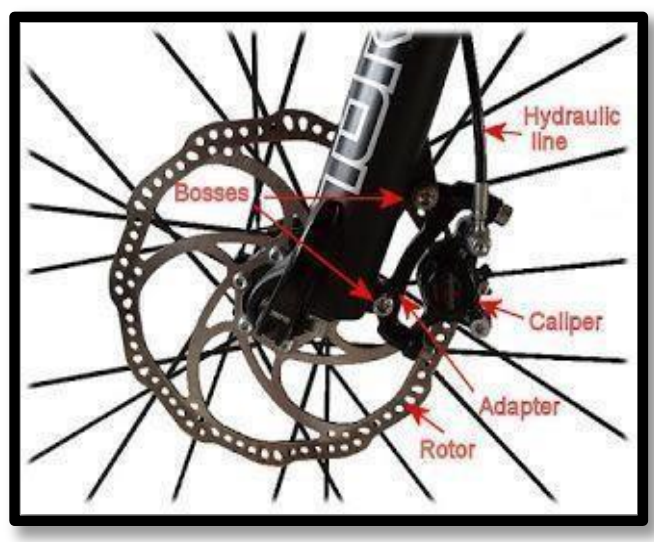




\section{International Advanced Research Journal in Science, Engineering and Technology}

Vol. 6, Issue 1, January 2019

4. Wheels and Drivetrain

Wheel size is an important factor constituting design of the trike. It contributes to the aspects of top load distribution and also the speed of the trike. Large wheels decrease rolling resistances and smaller wheels have less aerodynamic drag at high speeds and will allow for quicker acceleration. Thus, the rear wheel size was decided to be 28 inches and the front wheel size is to be 20 inches. The gear cassette is mounted on the rear wheel.

Cassette: Cassette is a cluster of gears which enable change of speeds manually using a derailleur assembly. The rear cassette used has 7 gear sprockets. A derailleur has been incorporated for efficient change of gears during operation of the trike.

Cadence: It is the number of revolutions of crank per minute. The cadence is directly proportional to the wheel speed and changes with the number of gears used. A high cadence was achieved by a gear combination of $7 * 1$ to reduce effort of the rider and slow twitch muscle recruitment. After taking in to consideration the chain

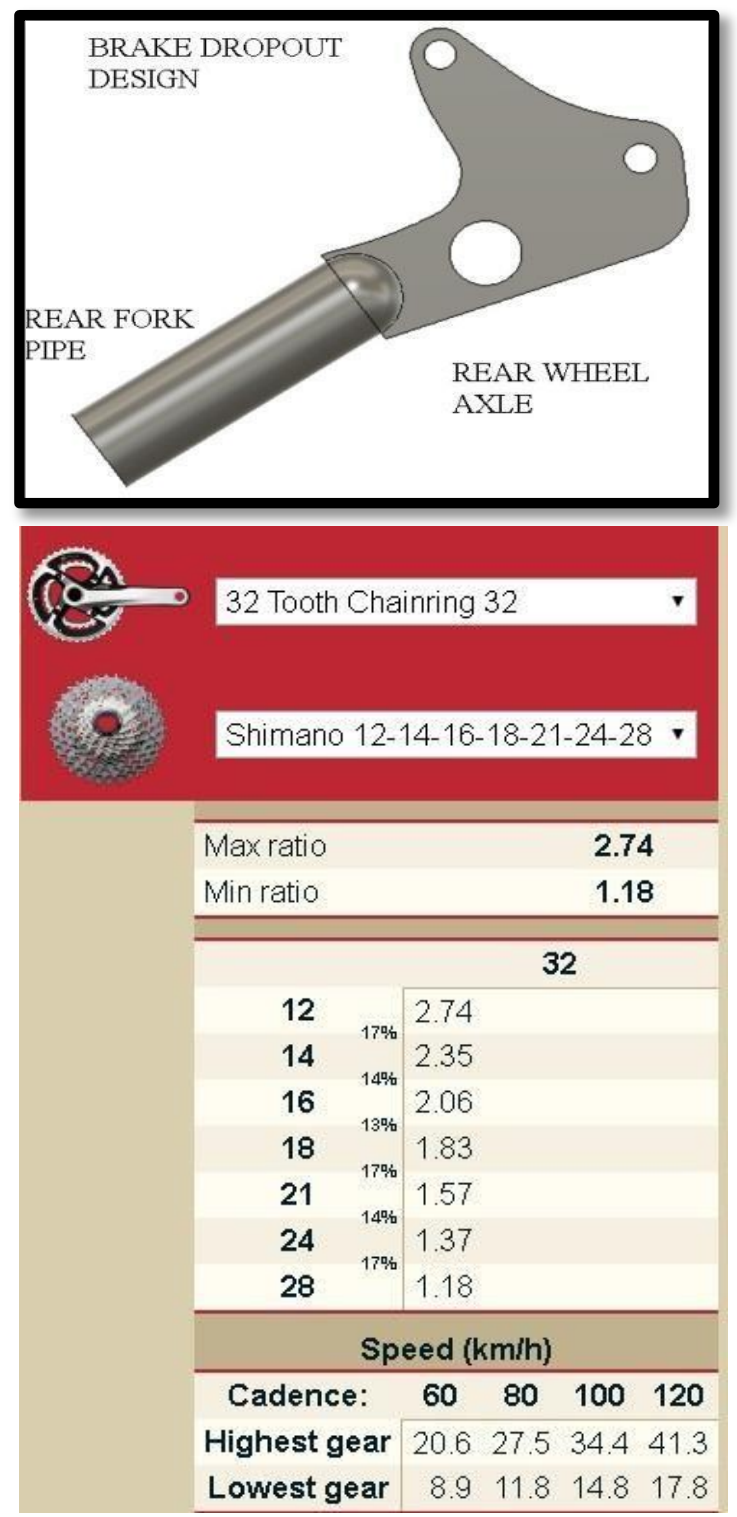

ring and cog specifications the following gear ratio was obtained for the combination. Single chain is used in combination with idler gears to transfer rider power to rear wheel. Idler gears help define the chain path. This is simple to design and manufacture. Chain tubing can be used to prevent the slack of chain and reduce the numberof idler gears. The chain routing shows the path followed by the chain during operation. It is depicted in the above figure. 


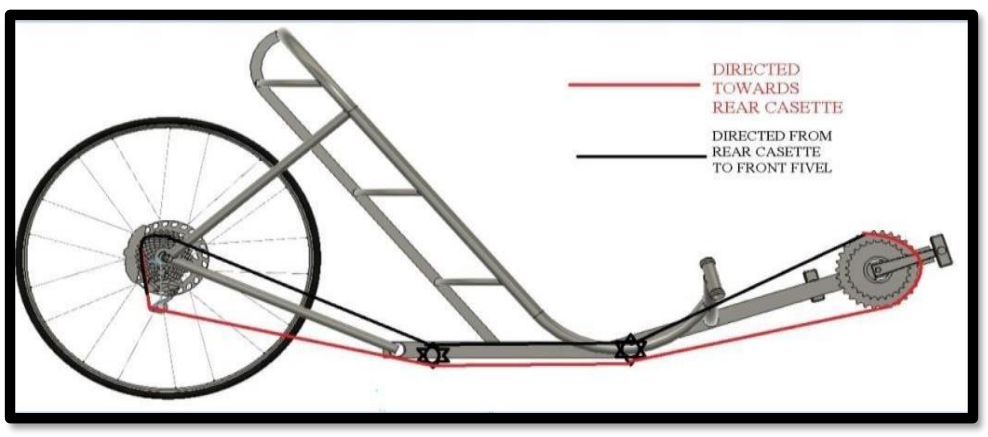

Analysis

1. RPS-

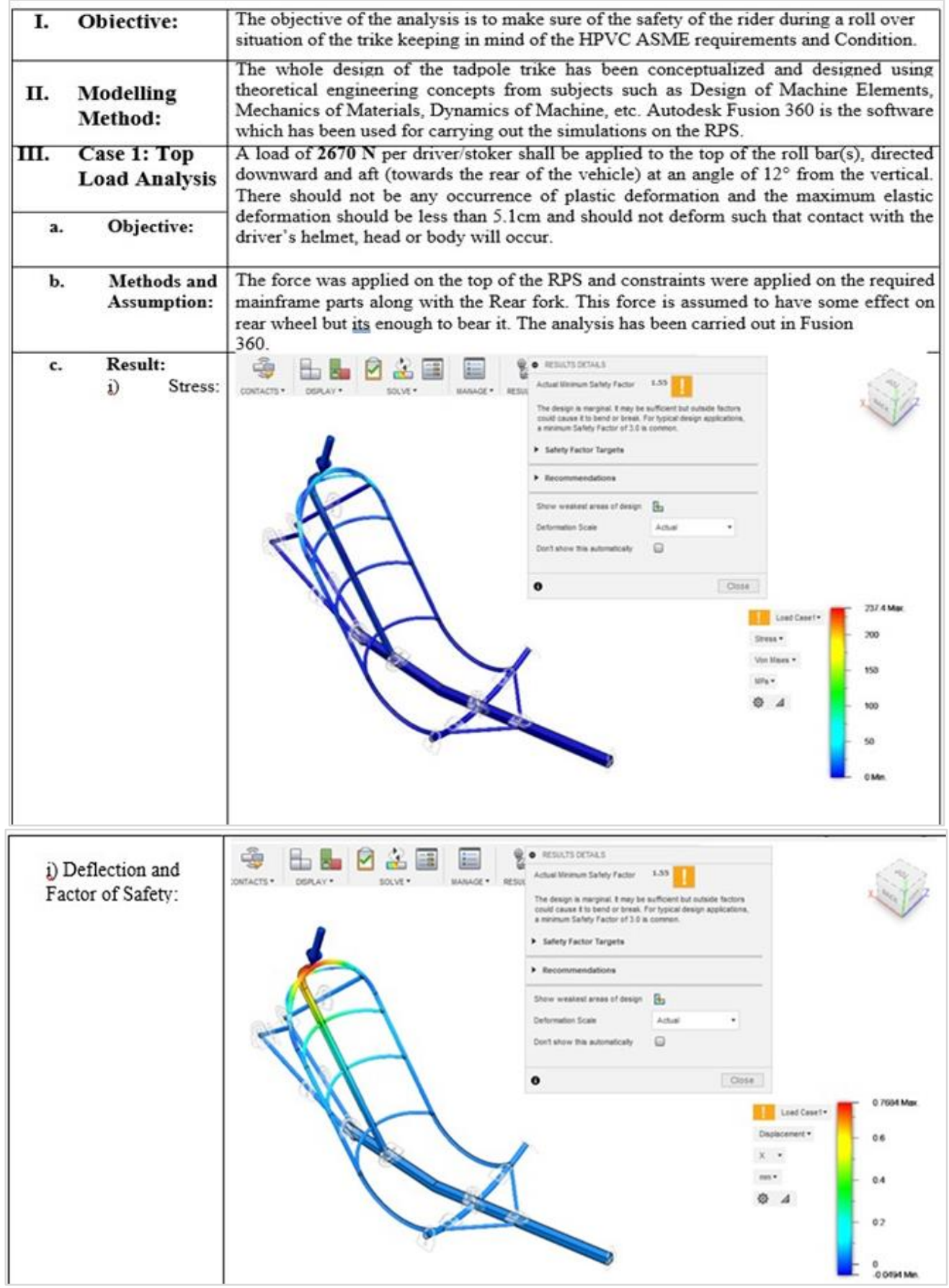


International Advanced Research Journal in Science, Engineering and Technology

Vol. 6, Issue 1, January 2019

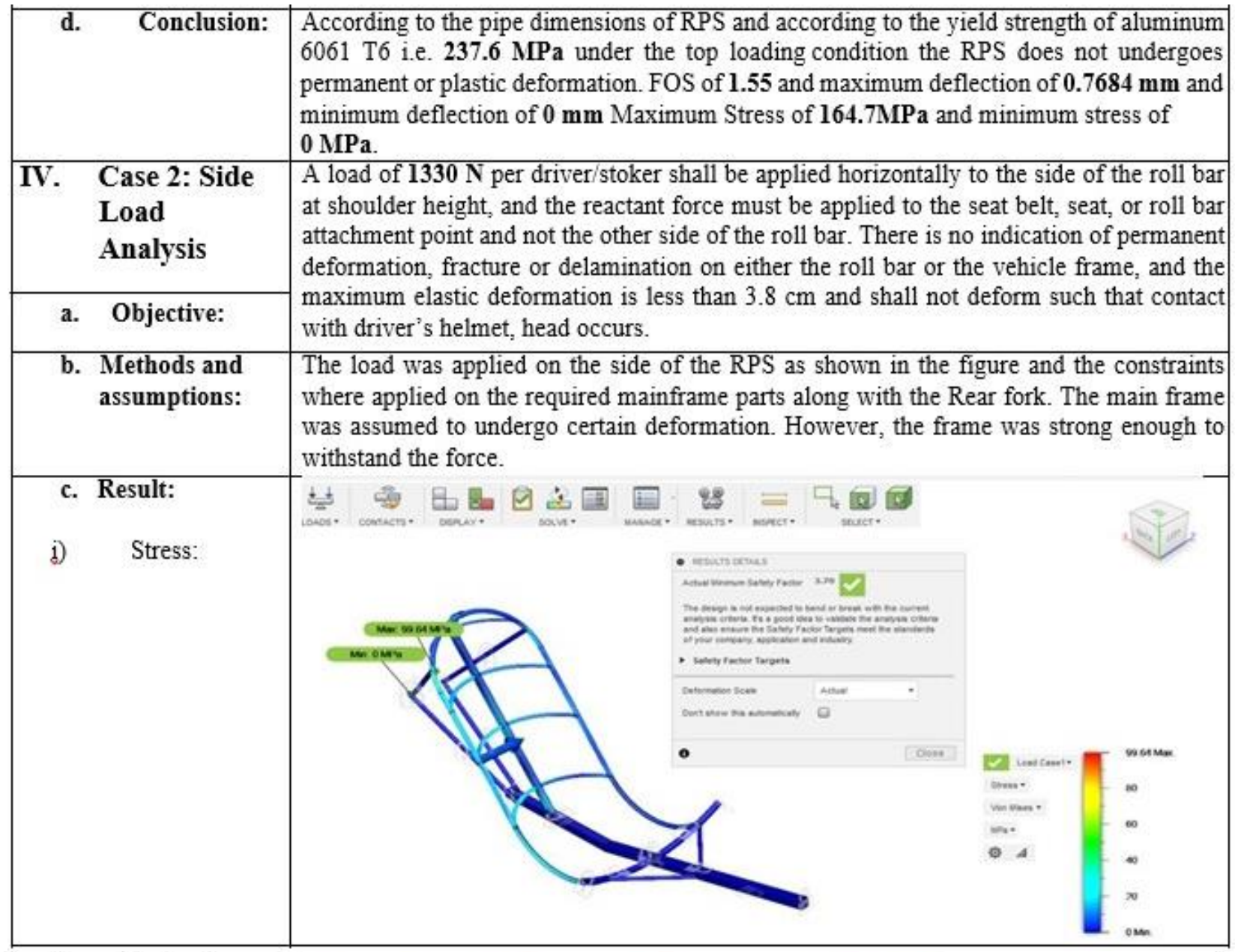

ii) Deflection
and Factor of
Safety:


Structural Analysis

1. Load on the Pedal-
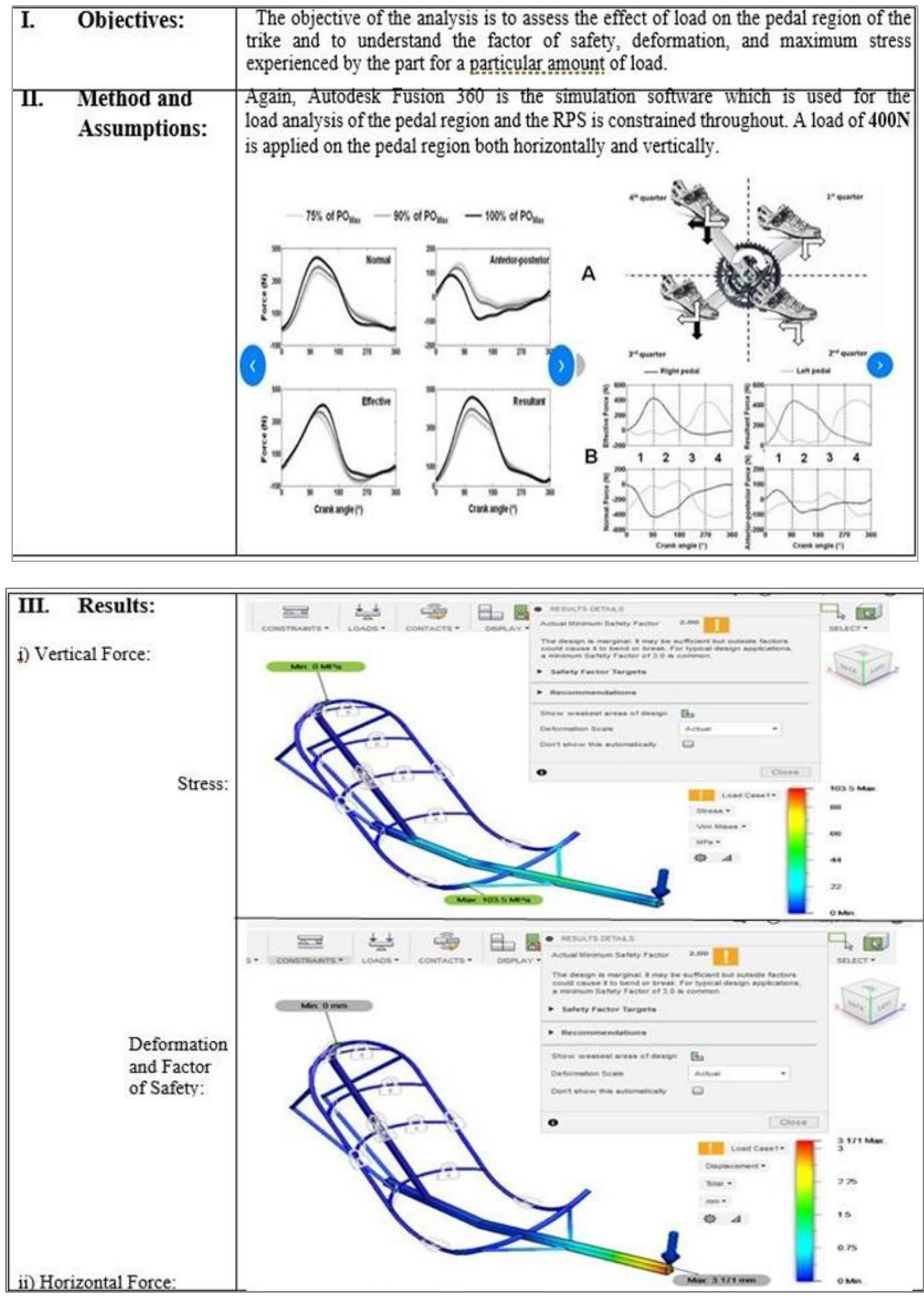


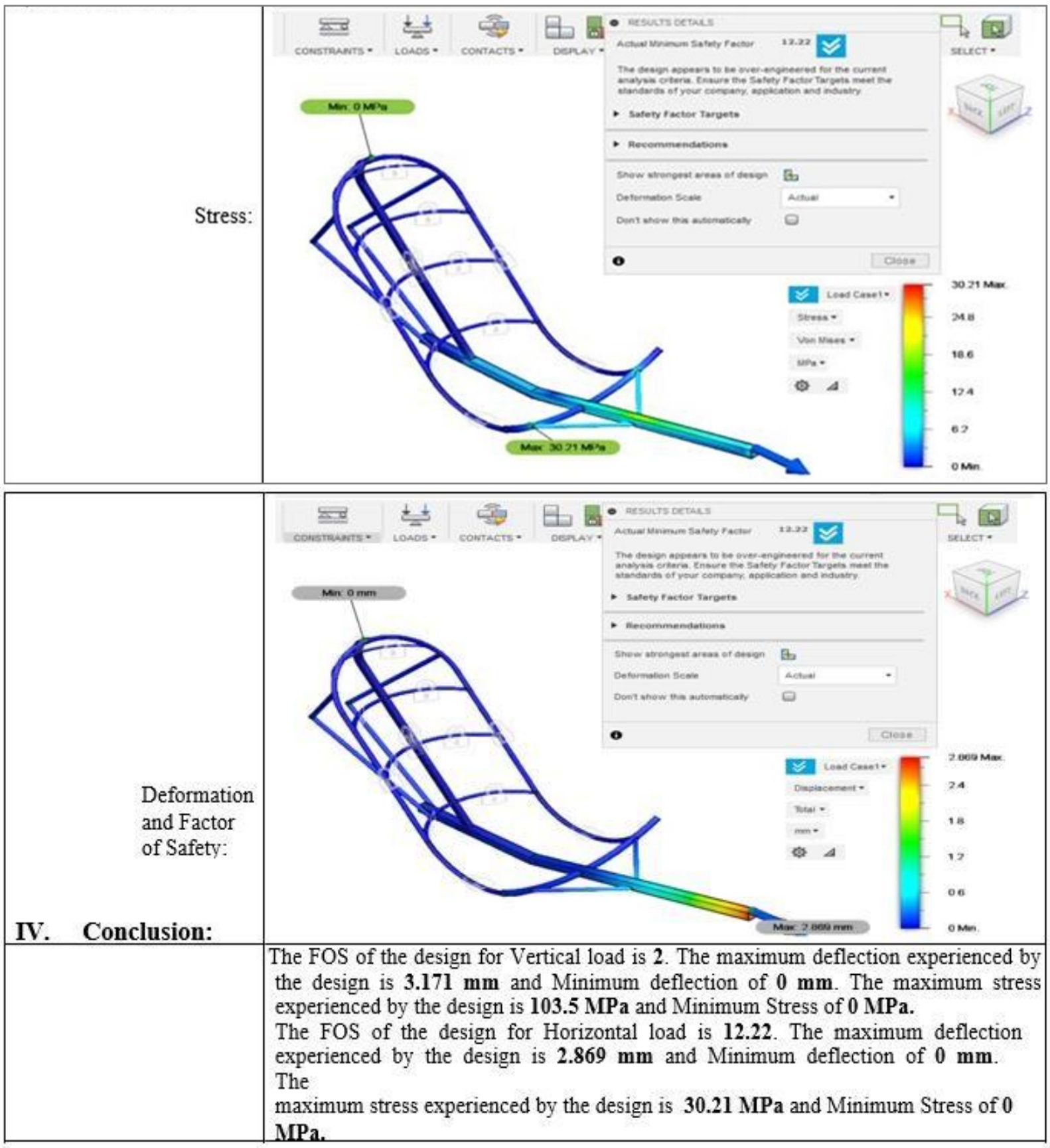

2. Load on the Kingpin

\begin{tabular}{|l|l|l|}
\hline I. Obiective: & $\begin{array}{l}\text { The objective of the analysis is to assess the effect of load on the kingpin and the rear } \\
\text { wheel axle region of the trike and to understand the factor of safety, deformation, and } \\
\text { maximum stress experienced by the part for a particular amount of load. }\end{array}$ \\
\hline II. Methods and & $\begin{array}{l}\text { Autodesk Fusion } 360 \text { is the simulation software which is used for the load analysis of } \\
\text { Assumptions: } \\
\text { the kingpin and the rear wheel axle region having } 66 \% \text { of the weight on the front axle } \\
\text { and } 33 \% \text { on the rear and the central pipes of the frame is constrained throughout. A } \\
\text { load of } 900 \mathrm{~N} \text { is distributed and applied on the region. }\end{array}$ \\
\hline
\end{tabular}


International Advanced Research Journal in Science, Engineering and Technology

Vol. 6, Issue 1, January 2019

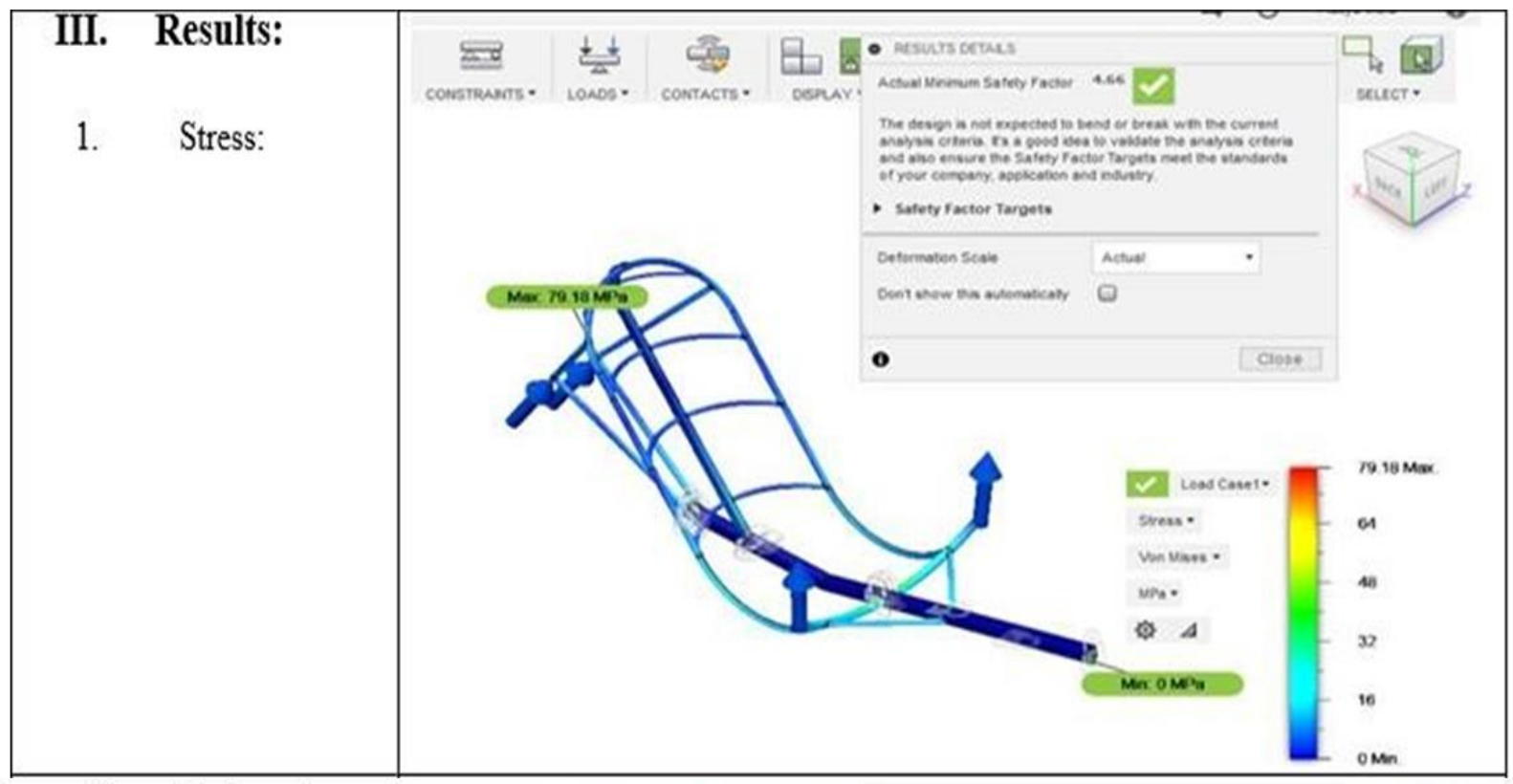

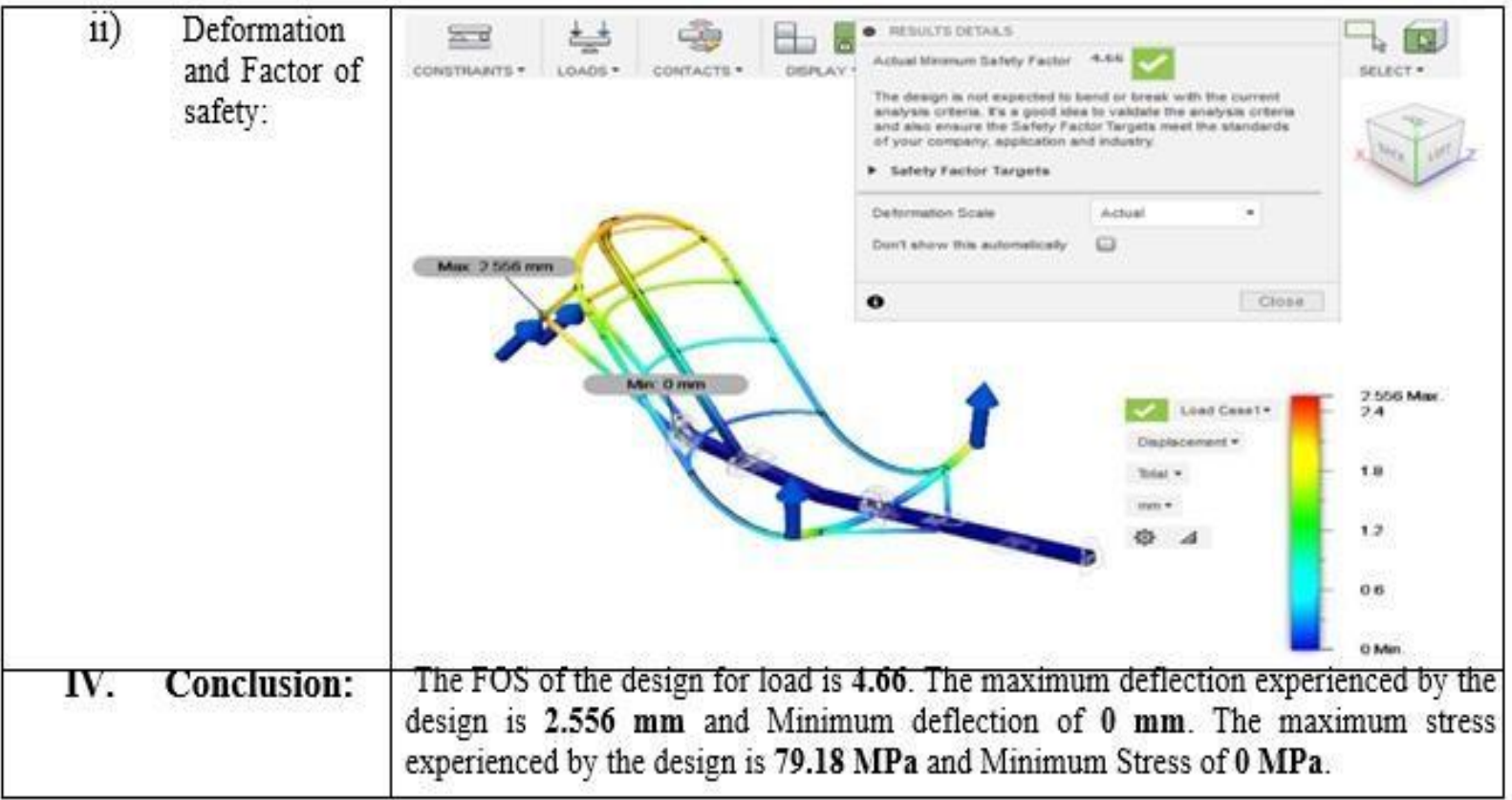

Aerodynamic Analysis

I. Objective: The objective of the analysis is to ensure that the fairing can accommodate the tallest rider of the team and to also make sure that there is decrease in the drag force by minimizing differences in the pressure.

II. Methods and ANSYS fluent CFD software was used for the analysis and the analysis was Assumptions: performed iteratively multiple fairing. 
International Advanced Research Journal in Science, Engineering and Technology

Vol. 6, Issue 1, January 2019

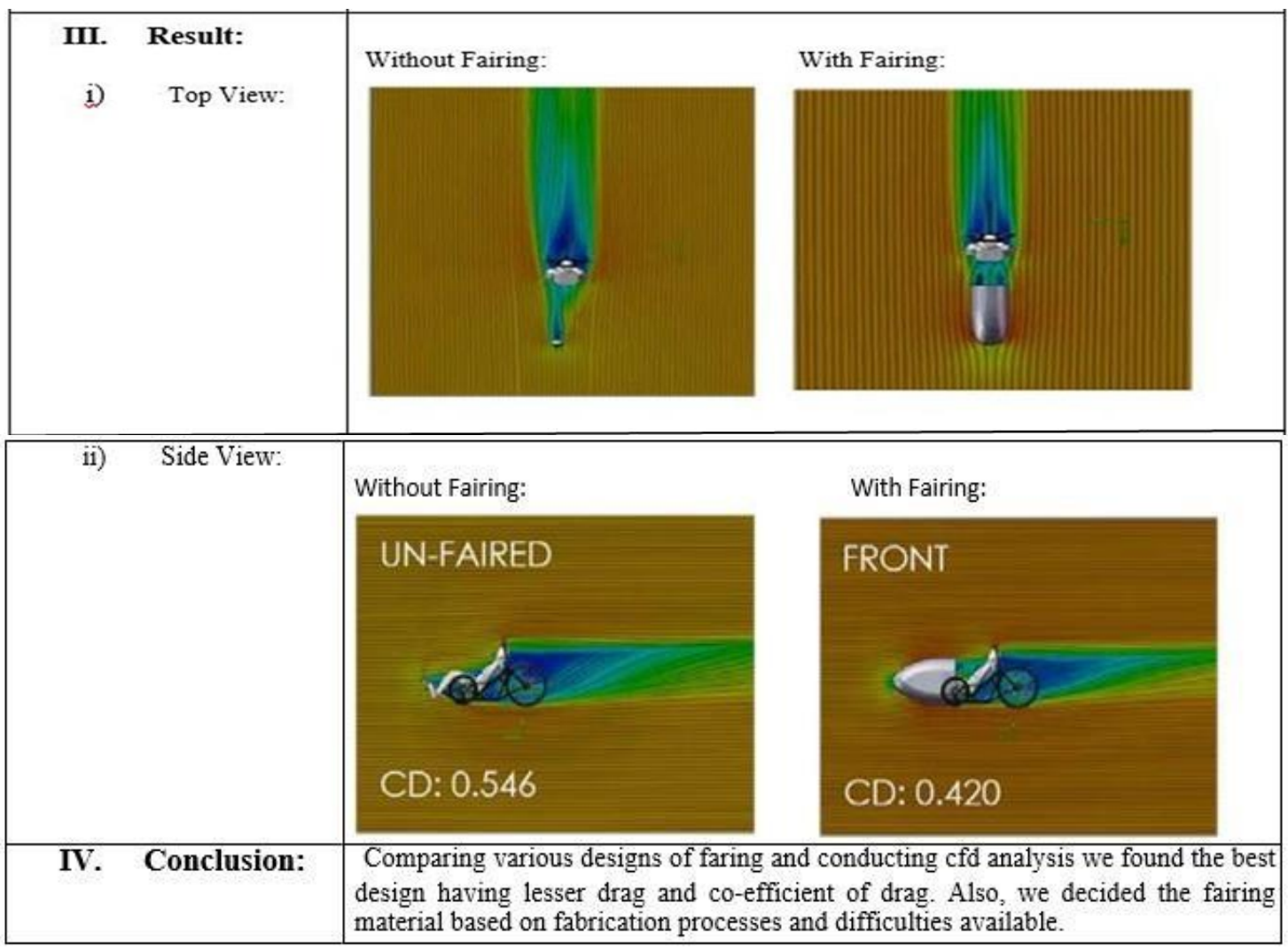

Steering Analysis

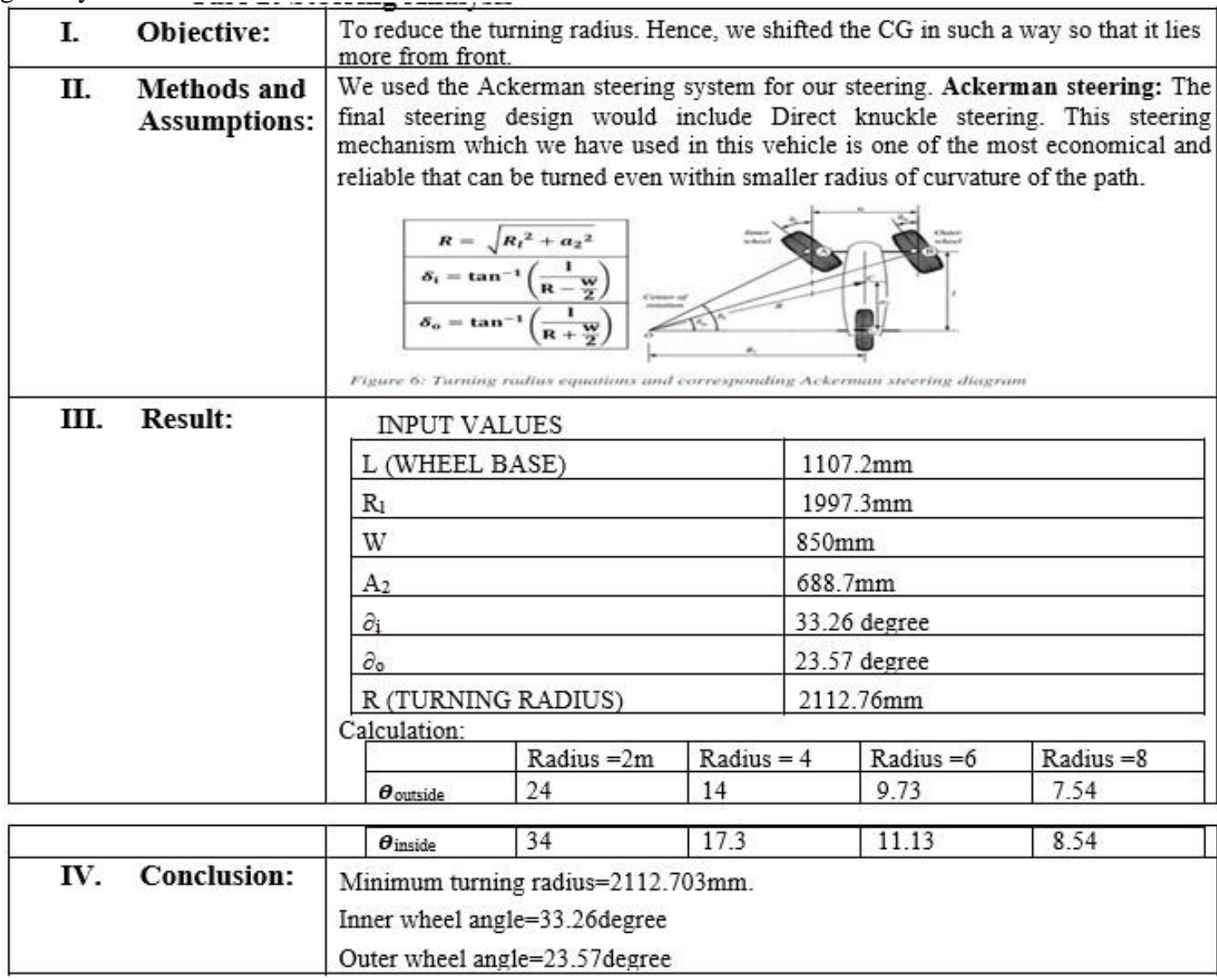


3D Drawing
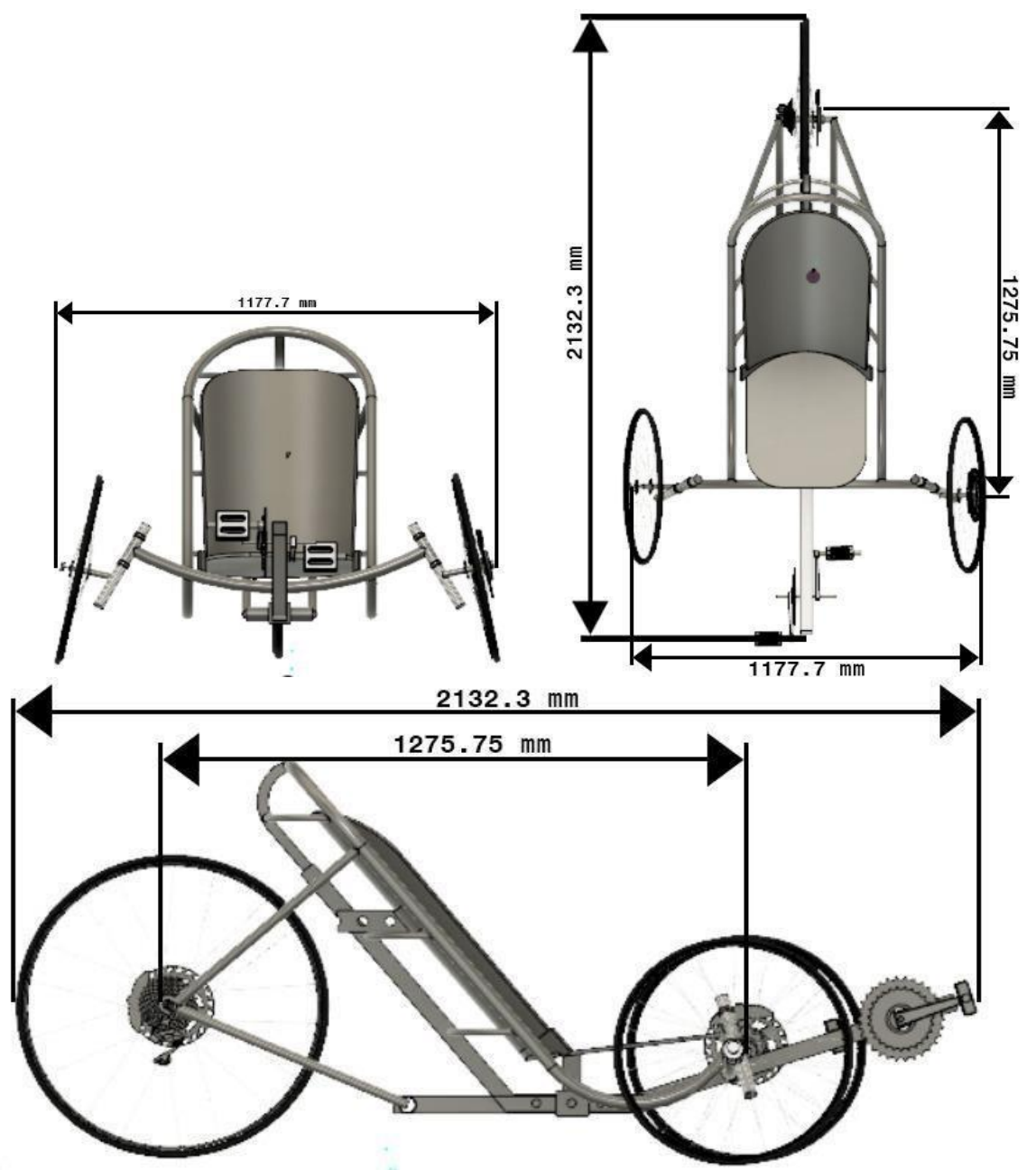

Figure 1- Front View Figure 2- Top View Figure 3- Side View

\section{CONCLUSION}

A. Comparison

\begin{tabular}{|c|c|}
\hline ANALYTICAL PERFORMANCE & EXPERIMENTAL RESULTS \\
\hline $\begin{array}{l}\text { RPS is expected to hold a top load of } 2760 \mathrm{~N} \text { and } \\
\text { a side load of } 1330 \mathrm{~N} \text { without undergoing any } \\
\text { permanent deformation. }\end{array}$ & $\begin{array}{l}\text { RPS successfully holds a top load of } 2760 \mathrm{~N} \\
\text { and a side load of } 1330 \mathrm{~N} \text { without forming any } \\
\text { permanent deformation. }\end{array}$ \\
\hline $\begin{array}{l}\text { The load on the pedal is expected to hold a } \\
\text { load of } 400 \mathrm{~N} \text { and the kingpin is expected to } \\
\text { handle a force of } 900 \mathrm{~N} \text { without forming any } \\
\text { deformation. }\end{array}$ & $\begin{array}{l}\text { The pedal and the kingpin successfully handle } \\
\text { the load without any deformation or breakage. }\end{array}$ \\
\hline $\begin{array}{l}\text { Center of gravity is expected to be in the } \\
\text { abdomen region of the rider. }\end{array}$ & $\begin{array}{l}\text { The center of gravity is found to be exactly at } \\
\text { the desired location. }\end{array}$ \\
\hline $\begin{array}{l}\text { Turning radius is expected to be } 2.11 \mathrm{~m} \text { which is } \\
\text { below the } 8 \mathrm{~m} \text { limit set by ASME. }\end{array}$ & $\begin{array}{l}\text { Turning radius is found to be around } 2 \mathrm{~m} \\
\text { which is close to the analytical radius. }\end{array}$ \\
\hline $\begin{array}{l}\text { The vehicle is expected to stop within } 6 \mathrm{~m} \text { at } \\
25 \mathrm{kph} \text { when a braking force of } 528 \mathrm{~N} \text { is } \\
\text { applied. }\end{array}$ & $\begin{array}{l}\text { The vehicle stops within } 6 \mathrm{~m} \text { at } 25 \mathrm{kmp} \text {, which is } \\
\text { the desired distance. }\end{array}$ \\
\hline
\end{tabular}

B. Evaluation: The results of the final testing of the vehicle were satisfactory as all of them were exact or very close to our theoretical analysis. The vehicle was put in a Universal Testing Machine (UTM) for physical testing and we 


\section{International Advanced Research Journal in Science, Engineering and Technology}

Vol. 6, Issue 1, January 2019

got the desired results proving that the vehicle is strong. The RPS was tested from all required directions which did not get deformed at any point proving the vehicle to be safe for the rider. The safety requirements such as safety harness, field of vision and absence of sharp edges and protrusions is met.

\section{REFERENCES}

[1]. www.recumbents.com

[2]. Recumbent Trike designer by Rickey D Horwitz

[3]. www.ihpva.org

[4]. Automobile engineering by Kripal Singh.

[5]. Design of machine element part 1 and part 2 by J B K Das

[6]. https://www.defproc.co.uk/blog/2010/the- golden-rule-of-trike-design/

\section{Appendix}

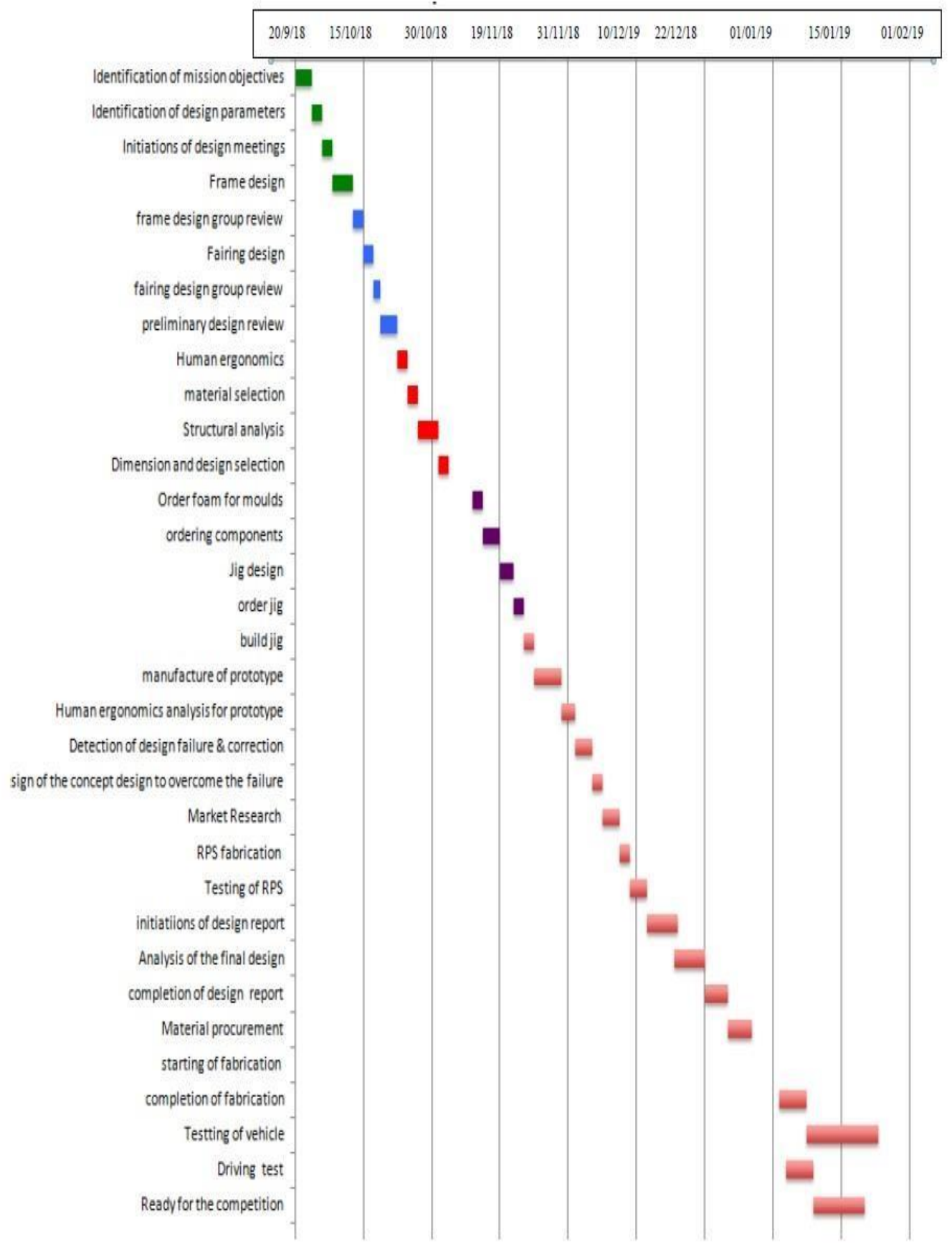

